\title{
Washington State Cable Median Barrier In-Service Study
}

\author{
Doug McClanahan \\ Washington State Department of Transportation \\ PO Box 47329 \\ Olympia Washington 98504-7329 \\ Tel: (360) 705-7264 \\ Fax: (360) 705-7330 \\ mcclando@wsdot.wa.gov \\ Richard B. Albin \\ Washington State Department of Transportation \\ PO Box 47329 \\ Olympia Washington 98504-7329 \\ Tel: (360) 705-7451 \\ Fax: (360) 705-7330 \\ albind@wsdot.wa.gov \\ John C. Milton \\ Washington State Department of Transportation \\ PO Box 47329 \\ Olympia Washington 98504-7329 \\ Tel: (360) 705-7299 \\ Fax: (360) 705-7330 \\ miltonj@wsdot.wa.gov
}

Submitted for presentation at the $83^{\text {rd }}$ Annual Meeting of the National Transportation Research Board, Washington D.C., 2004.

Estimated word count: 4080 text.

November 2003 


\author{
Washington State Cable Median Barrier In-Service Study \\ Doug McClanahan \\ Washington State Department of Transportation \\ Richard B. Albin \\ Washington State Department of Transportation \\ John C. Milton \\ Washington State Department of Transportation
}




\begin{abstract}
Since 1989, the American Association of State Highway and Transportation Engineers (AASHTO) Roadside Design Guide has contained information on a cable median barrier design that mounts the middle cable on the back side of the posts so that it can contain and redirect vehicles that strike the system from either side. Cable median barrier has been tested in accordance with NCHRP Report 350 Test Level 3. However, there are only a couple of studies that have been performed on the in-service performance of this system.

This report documents Washington's experience with cable median barrier by analyzing its initial installation cost, maintenance costs, maintenance experiences, and accident history before and after installation. The report is based on accident and maintenance report data associated with 24.4 total miles of cable median barrier located in three distinct locations along Interstate 5 (I-5).

Cable median barrier installation cost was calculated to be approximately $\$ 44,000$ per mile. The average cost per repair was found to be $\$ 733$ and the maintenance repair cost per mile was found to be $\$ 2,570$ annually. The time between cable barrier damage notification and repair was estimated to be about 2 days and the time required to repair it was about 30\% less than that required for $\mathrm{W}$-beam guardrail. The societal benefit of cable median barrier was calculated to be $\$ 420,000$ per mile annually. Given the societal benefits associated with the use of cable median barrier at locations having prior cross median accidents, cable median barrier has been found to be a cost effective solution to median crossover accidents.
\end{abstract}




\section{INTRODUCTION}

Cable barriers have been used on the nation's highways since the 1930's or before. The modern system, which uses 3 cables supported by weak steel posts was developed in the 1960's and has been used significantly by several states. Since 1989, the American Association of State Highway and Transportation Engineers (AASHTO) Roadside Design Guide (1) has contained information on a cable median barrier design that mounts the middle cable on the back side of the posts so that it can contain and redirect vehicles that strike the system from either side. Cable median barrier has been tested in accordance with NCHRP Report 350 Test Level 3 (2). However, there have been only a few studies published about the in-service performance of this system.

\section{PREVIOUS RESEARCH}

A study of the cable median barrier in North Carolina (3) was conducted by developing several regression-type models to estimate the effects of the barrier. This study found that several types of crashes (such as ran-off-road-left, hit fixed object) increased on the sections where cable median barrier was installed. However, an overall improvement in safety was found because there were fewer serious and fatal crashes.

The Oregon Department of Transportation studied of cable median installed on I-5 near Salem, Oregon (4). This study evaluated the number and severity of crashes before and after the cable median barrier was installed. This comparison showed a significant decrease in severe accidents after the barrier was installed. The installation cost for this barrier was approximately $\$ 42,000$ per mile and the repair costs were approximately $\$ 4250$ per mile per year. The study concluded that the cable median barrier is recommended for use in locations where the median width exceeds 23 feet.

Although many different types of median barriers are used in the United States, cable median barrier is relatively new to Washington State. This report documents Washington's experience with cable median barrier by analyzing its initial installation cost, maintenance costs, maintenance experiences, and accident history before and after installation. The report is based on accident and maintenance report data associated with 24.4 total miles of cable median barrier located in three distinct locations along Interstate 5 (I-5). The first segment is located to the north of Vancouver, Washington, the second is located between Tacoma and Seattle, and the third is located north of Everett.

\section{CABLE MEDIAN BARRIER DESIGN}

In the early 1990's, the Washington State Department of Transportation (WSDOT) became interested in installing barrier in medians that are over 30 feet wide where there was a history of cross median accidents. The cable median barrier was selected as a low cost alternative for these locations. In addition, cable median barrier is thought to be more aesthetically acceptable than other barrier designs and does not increase the impervious area and subsequent environmental mitigation associated with concrete barrier. As a result, WSDOT sponsored crash tests to evaluate the performance of median cable barrier in accordance with 
NCHRP Report 350 (2) criteria (using a small 1800 pound car and a 4400 pound pickup truck). In both tests, the vehicles were contained and brought to a stop within less than 12 feet of deflection. The occupant risk values were within the preferred limits set by NCHRP 350 and the damage to both vehicles was relatively minor (5).

The Washington State cable median barrier consists of three 3/4 inch diameter cables supported by S3 x 5.7 x 5'-3” long posts. Installation height from the ground surface to the bottom and top cables is 21 inches and 30 inches respectively with the middle cable evenly spaced between them. The middle cable is mounted on the opposite side of the posts. The posts in this system are typically spaced 16 feet on-center (see Figure 1). The system can be placed in the middle of the median or it can be offset. Both systems are used in Washington with the central location chosen where maintenance, grade separation, or slope allows.

The terminal designs used by WSDOT for cable barriers are nearly identical to the terminals approved by the FHWA (7). The ends of the cables are attached to turnbuckle assemblies that are bolted to a breakaway anchor angle and anchored rigidly to a concrete footing (see Figure 2). Spring cable end assemblies are installed on the ends of the cables and the barrier runs are limited to 2000' between the terminals. Compressing the springs introduces tension in the cables, and thus they are designed to compensate for temperature variations. The WSDOT has also developed a transition to W-beam guardrail, based on South Dakota's design (see Figure 3).
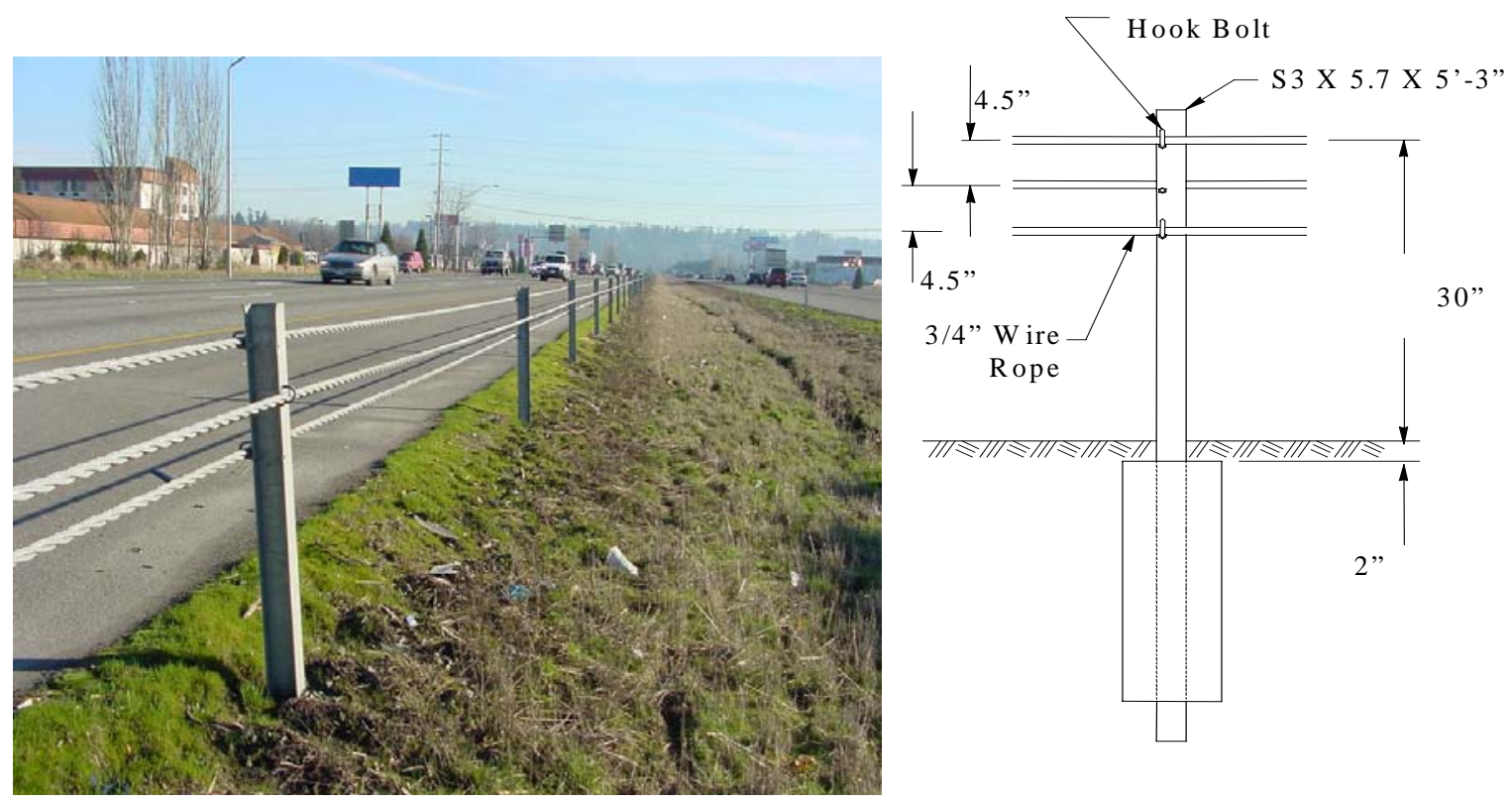

FIGURE 1 Typical cable median barrier installation and details 

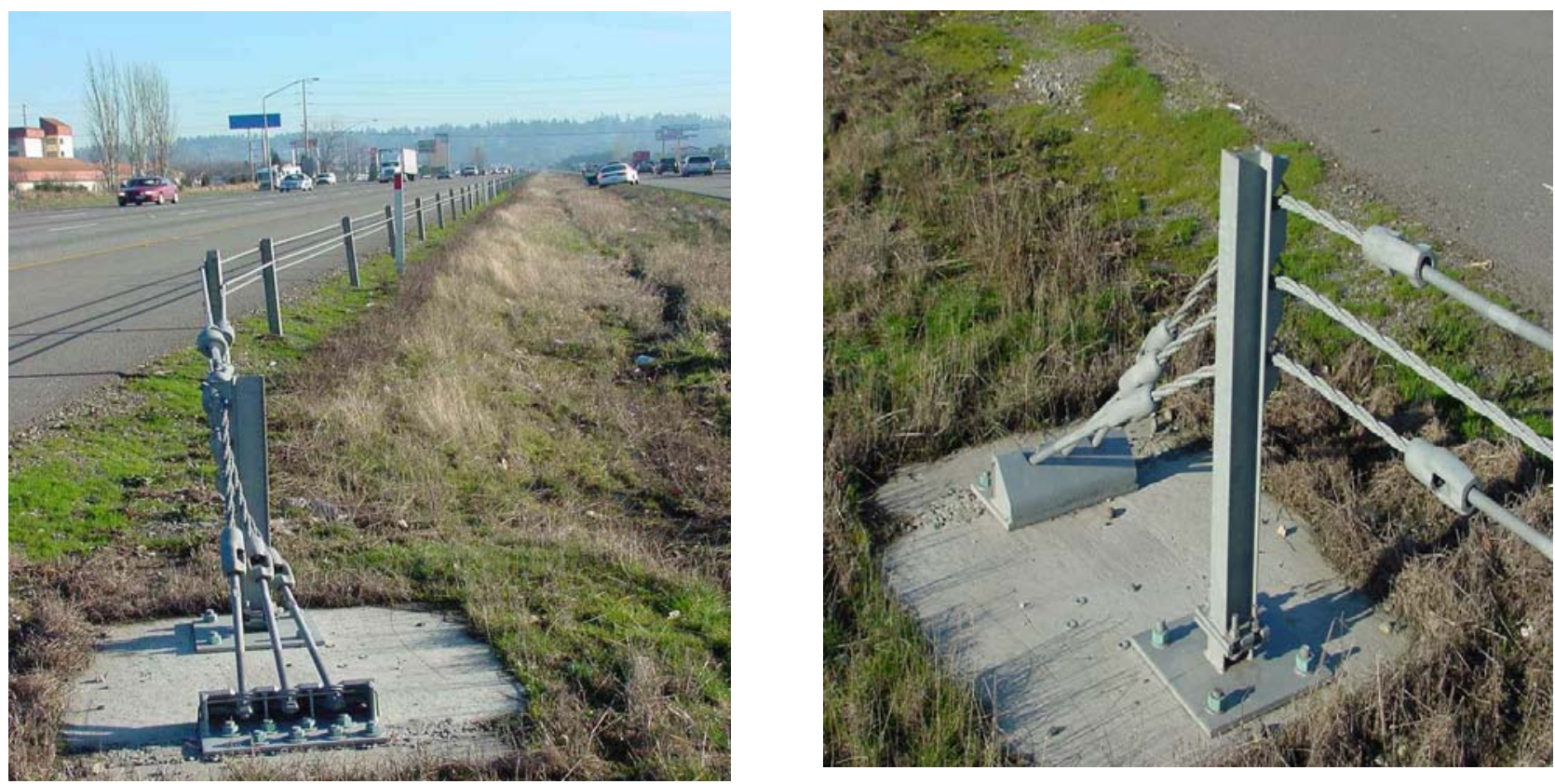

FIGURE 2 Washington State cable barrier terminal
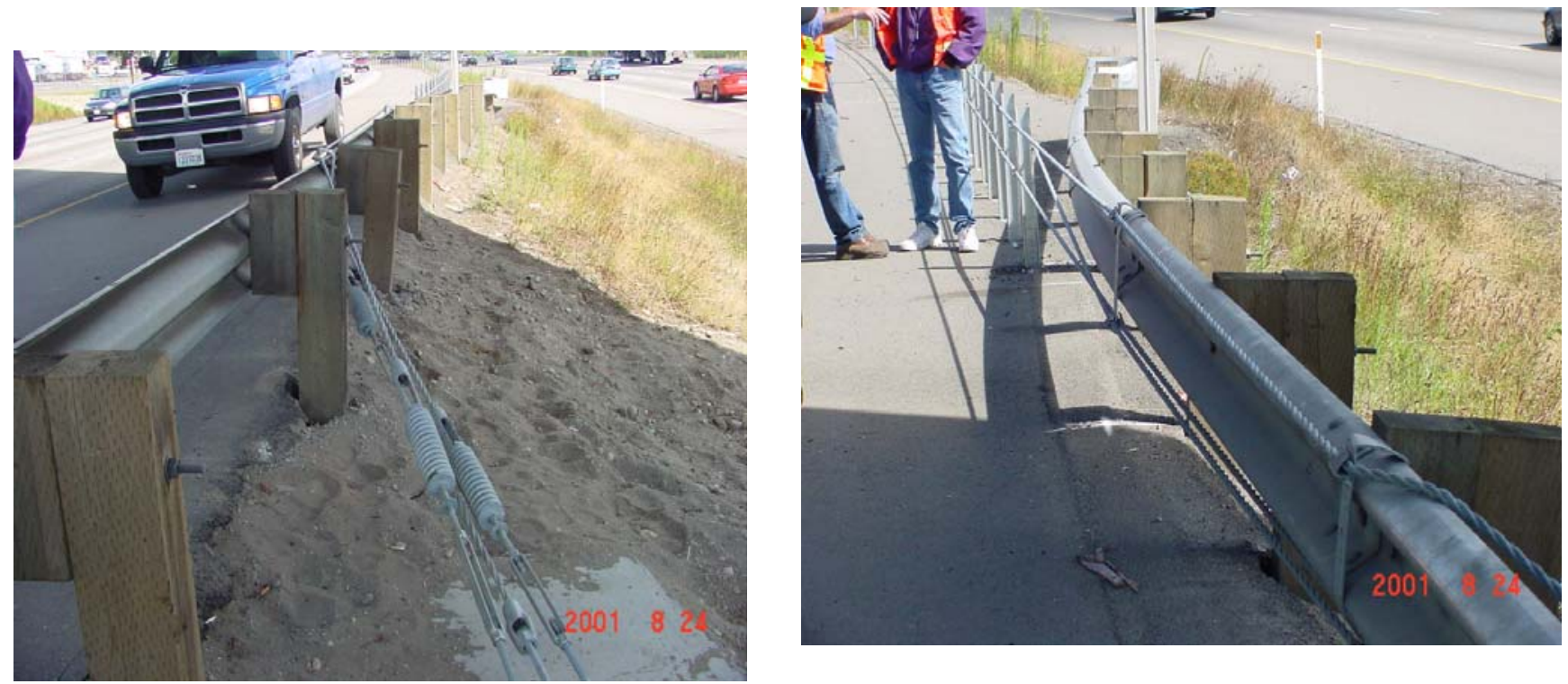

FIGURE 3 Washington State cable barrier transition to W-beam guardrail

\section{BARRIER COSTS}

Cable barrier costs are predominantly fixed and operational. The fixed costs are installation and the operational costs are maintenance. 


\section{Barrier types and installation costs}

Quantifying the differences in the various systems’ initial costs was accomplished with the aid of the WSDOT Unit Bid History. Unit bid prices do not include mobilization, traffic control, and engineering. This system was used to find the state average bid price for cable median barrier, precast concrete barrier, W-beam guardrail, cast in place and single slope concrete barrier:

- Cable median barrier:

- W-beam guardrail:

- Precast concrete barrier:

- Single Slope concrete barrier:

- Cast in Place concrete barrier:
$\$ 8.33 / \mathrm{ft}$ or $\$ 44,000 / \mathrm{mi}$

$\$ 13.65 / \mathrm{ft}$ or $\$ 72,000 / \mathrm{mi}$

$\$ 24.64 / \mathrm{ft}$ or $\$ 130,000 / \mathrm{mi}$

$\$ 44.94 / \mathrm{ft}$ or $\$ 237,000 / \mathrm{mi}$

$\$ 79.36 / \mathrm{ft}$ or $\$ 419,000 / \mathrm{mi}$

Costs for cable barrier terminals are about the same as guardrail terminals - roughly $\$ 1,700$ so they do not appear to be a relevant fixed cost factor. If an impact attenuator is used to terminate a guardrail or concrete barrier, the terminal costs can be much more expensive.

\section{CABLE MEDIAN BARRIER MAINTENANCE}

There are differing opinions from maintenance crews concerning the cable barrier. As it was a new system for Washington State, it required maintenance to stock additional parts (posts, bolts, etc) that were not used in other barriers. It also required training to understand the system. The barrier system was initially perceived by maintenance crews to be a higher maintenance system and generally, they objected to the initial installation of this barrier. This study determined the maintenance costs for the system and gathered input from the maintenance crews after the system had been in place for a period of time.

\section{Cable Median Barrier Maintenance Costs}

The WSDOT maintenance staff generates repair reports for many facility specific hardware items. These maintenance reports are categorized by items such as guardrail, cable, and concrete barriers. Quantifying cable median barrier maintenance cost was accomplished by tracking these maintenance reports. Maintenance staff compiled 141 cable barrier related maintenance reports for cable barrier damage on I-5 during the cable median barrier study period.

A maintenance repair does not always result in the generation of an accident report. In comparing cable median barrier repairs with accident reports, it was found that $51 \%$ of repairs documented by maintenance reports were able to be matched with an accident report. This results in a finding that is consistent with the Ray et al study (6) which stated that 54\% of all cable barrier accidents were reported. When a cable median barrier repair did not generate an accident report, it was found that fewer posts were hit, less repair time was required, and less parts and total repair costs resulted. 
Table 1 summarizes average, minimum, and maximum cost for all cable median barrier accidents identified by maintenance reports on I-5. Total repair costs include parts, labor, and equipment costs. Hours for repair are stated in man-hours:

$\begin{array}{lccc} & \text { Max. } & \text { Min. } & \text { Ave. } \\ \text { Number of posts hit: } & 32 & 1 & \mathbf{6 . 7} \\ \text { Hours for repair: } & 70 & 1 & \mathbf{9 . 4} \\ \text { Parts costs: } & \$ 1,490 & \$ 32 & \mathbf{\$ 3 2 8} \\ \text { Total repair costs: } & \$ 2,822 & \$ 72 & \mathbf{\$ 7 3 3}\end{array}$

TABLE 1 Cable barrier maintenance data

\section{Maintenance Experience Review Summary}

Although the maintenance cost information obtained from the maintenance reports is valuable, maintenance staff experiences are also important in assessing barrier performance. The maintenance experience for the cable median barrier study was captured through the use of questionnaires which were sent to maintenance supervisors in each maintenance area that had cable median barrier. The maintenance crew knowledge and opinions gained from these questionnaires are summarized below:

- When asked if they had any general comments about the system itself or the maintenance of the system, the following comments were received:

1. We were initially opposed to the cable barrier installation in our area.

2. We now support additional cable barrier in our Region, and are considering taking on some cable barrier installation work in conjunction with our Traffic Office.

3. Wide shoulders contribute significantly to the efficient scheduling of our cable barrier repair program in Tacoma - no lane closures are required, we can accomplish repairs during regular work hours, and we are not required to give public notice a week in advance of our work in this area.

- When cable median barrier is used for long-term temporary locations (locations where widening is anticipated in the near future), most of the system can be pulled up and reused. This portability is considered to be quite an advantage. Moving the barrier can be accomplished with relative ease compared to heavy concrete barrier or cumbersome guardrail.

- Cable barrier was rarely hit more than once before being repaired (due to either multiple car accidents or delay between a hit and repair).

- It was generally thought that there was not much difference in time, equipment, parts, storage requirements etc. between cable barrier and either concrete or guardrail systems however on a few occasions, maintenance staff had to wait a couple of weeks for parts. No specialized equipment was needed to maintain the system. 
- Most did not notice any difference in crew exposure to traffic between cable, concrete or guardrail systems. One Region noted that crew exposure is estimated to have been cut by at least $30 \%$ when repairing cable barrier as compared to other barrier types due to quicker repairs.

- The only differences in dealing with system components between cable concrete or guardrail systems was cited as being related to cable tensioning (unsure about how temperature affected tensioning) and post stability after replacement.

- Regarding terminals, anchors and anchor blocks, most had no issues but one mentioned that the anchors took more time to repair than the posts and one mentioned that an anchor block was loosened and showing signs of movement. (This is most likely due to the placement of the specific terminal in a median containing a slope and possibly a high water table)

- It was estimated that between $75 \%$ and $95 \%$ of repairs were accomplished within a week but most repairs were completed within 2 days of notification.

- Most had no recommendations for design or application changes for cable barrier, guardrail or concrete barrier.

- No one has ever been injured repairing the system.

\section{ACCIDENT EXPERIENCE}

The collection of maintenance reports was noted above but maintenance reports only contained information specific to the roadside safety hardware. When maintenance reports could be matched with accident reports, much more information was obtained. Examples are: date, time, collision type, contributing cause, number and severity of injuries, number of fatalities, number of vehicles involved, weather, speed, etc.

\section{Before and After Comparison}

The purpose of the median barrier is to reduce cross over accidents as they tend to result in more serious injuries than other types of collisions. However, it is generally accepted that installing a barrier where one did not exist before can result in more reported accidents as vehicles that may have otherwise recovered without crossing the median would be impacting the barrier. To evaluate the before and after accident history of the cable median barrier, it was necessary to compare these different accident types.

Another issue of note is that with the limited time available between the installation of the segments of cable barrier and the end of the study, a potential exists for the study results to regress to the mean. Washington will continue to monitor for this potential and update the study if regression to the mean becomes an issue

The accident history was based on accident information retrieved from the WSDOT accident database. A more detailed review of accident reports was conducted for all of the barrier related accidents involving fixed objects, cable barrier (after time frame only), crossovers, and rollovers. A comparison of these accident types is summarized in Table 2. It should be noted that although years 1990 through 1996 and years 1999 through 2002 are 
considered to have complete accident data in the WSDOT accident database, years 1997 and 1998 are considered incomplete due to a change in the reporting system during those years.

Median Accidents Before the Installation of Cable Barrier

\begin{tabular}{|c|c|c|c|c|c|}
\hline & $\begin{array}{c}\text { annual } \\
\text { accidents }\end{array}$ & $\begin{array}{c}\text { accident } \\
\text { rate }(100 \\
\text { mvmt })^{\star}\end{array}$ & $\begin{array}{c}\text { annual } \\
\text { fatal } \\
\text { accidents }\end{array}$ & $\begin{array}{c}\text { annual } \\
\text { disabling } \\
\text { accidents }\end{array}$ & $\begin{array}{l}\text { annual societal } \\
\text { costs (all } \\
\text { severities, stated } \\
\text { in millions) }\end{array}$ \\
\hline all & 49.00 & 6.50 & 3.00 & 3.60 & $\$ 13.58$ \\
\hline fixed object & 25.60 & 3.40 & 0.60 & 1.00 & $\$ 6.45$ \\
\hline cable barrier & na & na & na & na & na \\
\hline rollover & 11.40 & 1.51 & 1.00 & 1.20 & $\$ 4.50$ \\
\hline crossover & 16.00 & 2.12 & 1.60 & 2.20 & $\$ 7.13$ \\
\hline
\end{tabular}

Median Accidents After the Installation of Cable Barrier

\begin{tabular}{|c|c|c|c|c|c|}
\hline & $\begin{array}{c}\text { annual } \\
\text { accidents }\end{array}$ & $\begin{array}{c}\text { accident } \\
\text { rate }(100 \\
\text { mvmt }{ }^{\star}\end{array}$ & $\begin{array}{c}\text { annual } \\
\text { fatal } \\
\text { accidents }\end{array}$ & $\begin{array}{c}\text { annual } \\
\text { disabling } \\
\text { accidents }\end{array}$ & $\begin{array}{l}\text { annual societal } \\
\text { costs (all } \\
\text { severities, stated } \\
\text { in millions) }\end{array}$ \\
\hline all & 100.43 & 13.35 & 0.33 & 1.76 & $\$ 3.32$ \\
\hline fixed object & 91.71 & 12.17 & 0.33 & 1.76 & $\$ 2.48$ \\
\hline cable barrier & 58.56 & 4.05 & $0.33^{*}$ & 0.88 & $\$ 3.44$ \\
\hline rollover & 9.40 & 1.25 & 0.33 & 0.65 & $\$ 1.71$ \\
\hline crossover & 3.83 & 0.51 & 0.00 & 0.33 & $\$ 0.18$ \\
\hline
\end{tabular}

TABLE 2 Median accidents before and after the installation of cable barrier

The sections of cable median barrier on I-5 were installed at different times and thus have different levels of exposure. In order to compare each cable median barrier segment, the data for each segment had to annualized. Five years of accident data were available for the period before each median cable barrier was installed. The minimum amount of accident data collection for the period after cable barrier installation was 1.54 years with the other segments ranging from 1.75 to 5 years of available data.

The time span for each median barrier segment is shown in Table 3.

\begin{tabular}{lccc}
\hline \multicolumn{1}{c}{ Segment } & $\begin{array}{c}\text { Length } \\
\text { (miles) }\end{array}$ & Median Width & $\begin{array}{c}\text { Years of analysis } \\
\text { before and after installation }\end{array}$ \\
\hline SR 5, N. Of Vancouver & 12.23 & $48-82$ feet & $5 / 1.54$ \\
SR 5, Between Tacoma \& Seattle & 2.10 & 48 feet & $5 / 1.75$ \\
SR 5, N. of Everett (phase1)* & 2.25 & 40 feet & $5 / 5.0$ \\
SR 5, N. of Everett (phase 2) & 10.10 & 40 feet & $5 / 3.0$ \\
\hline
\end{tabular}

* The two mile segment was installed in 1995. The segment was relocated and expanded to 10 miles. 


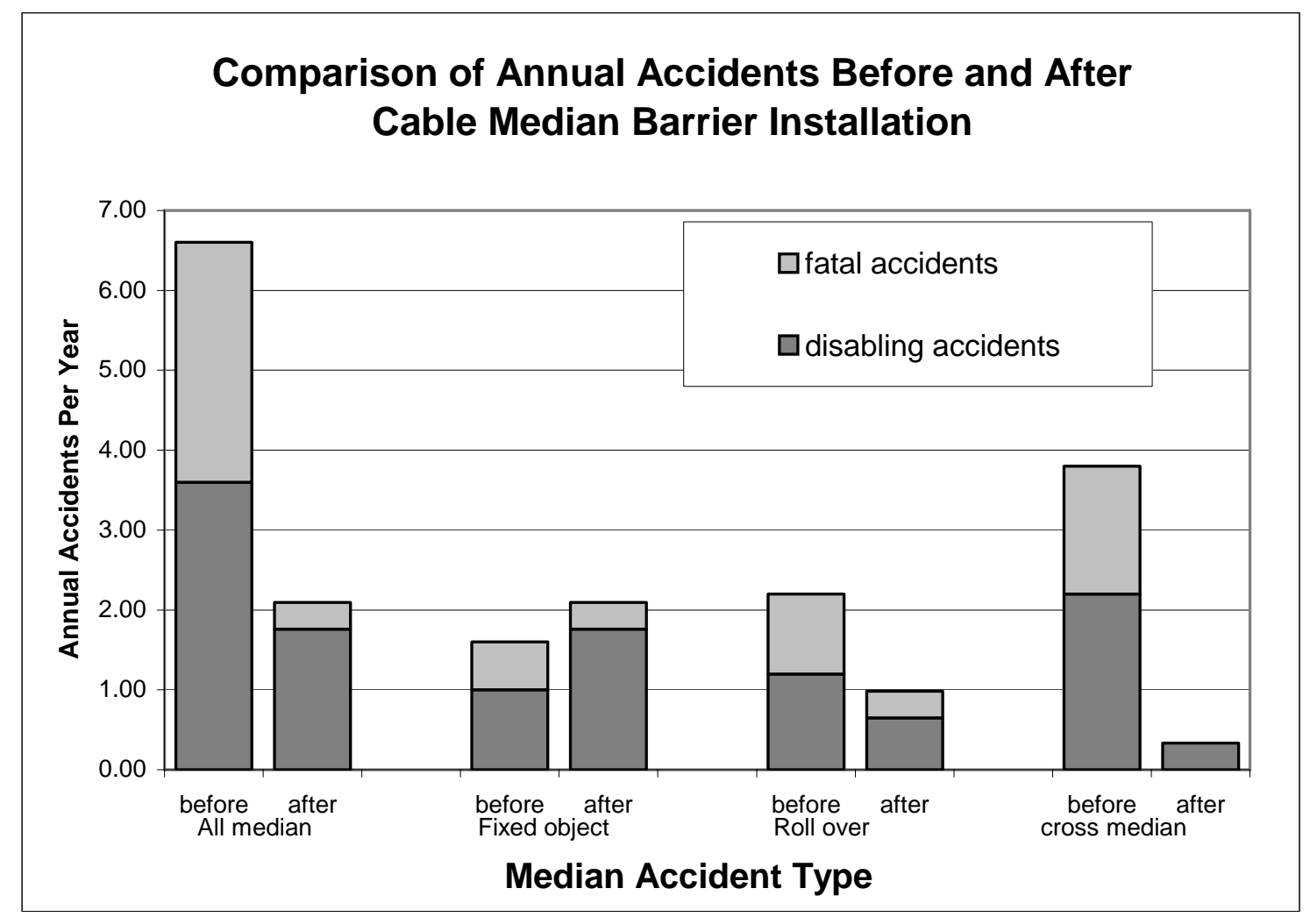

*The single fatality shown for the after time frame was determined to be due to a rollover. Further inspection of the accident revealed that wheel furrowing was present before impact with the cable barrier, which is likely the cause of the rollover. This fatality is represented in following fatal accidents after install categories above: "all", "fixed", and "rollover."

\section{FIGURE 4 Before and after accident comparison}

The calculated societal costs shown in Table 2 were based on the unit costs shown in Table 4. For all median related accidents, the annual societal costs were calculated to be $\$ 13.58$ million before the installation of cable barrier and \$3.32 million after the installation, which results in a savings of $\$ 10.26$ million annually. This results in a savings of $\$ 420,000$ per mile per year.

\begin{tabular}{rr}
\hline PER FATAL COLLISION & $\$ 3,760,000$ \\
PER DISABLING INJURY COLLISION & $\$ 315,000$ \\
PER EVIDENT INJURY COLLISION & $\$ 70,000$ \\
PER POSSIBLE INJURY COLLISION & $\$ 35,000$ \\
PER PROPERTY DAMAGE ONLY COLLISION & $\$ 6,500$ \\
\hline
\end{tabular}

Based on 1988 FHWA Recommendations and inflated to 2002 dollars

TABLE 4 Accident Societal Costs 


\section{Detailed Evaluation of Barrier Impacts:}

In addition to the Before/After evaluation, a detailed review of certain barrier impacts was conducted. The following are the findings from this review.

\section{Barrier:}

- Multiple Cable Strike (either multiple cars striking the barrier or the same car striking the barrier multiple times)

Four accidents involved vehicles that struck the barrier multiple times. None of the accidents resulted in barrier penetration.

- Terminal Strike

Two accidents involved vehicles that struck the barrier terminal. One accident resulted in an injury.

- Median Crossover (where vehicle travels across the median onto the oncoming lanes of travel or beyond)

Ten accidents involved vehicles that crossed the median. Of these accidents, three resulted in a collision with another vehicle traveling in the opposite direction, 3 involved a vehicle that rolled over, 2 involved speeding, and 1 involved a vehicle with a blown tire (prior to impact with the barrier). Two of the crossover accidents resulted in injuries.

\section{Vehicle:}

- Vehicle was Towing

There were five accidents involving vehicles that were towing. Though it is expected that many vehicles involved in towing can be heavier than the design vehicle of the cable barrier, in every case, the cable contained the errant vehicles and only one possible injury resulted.

- Vehicle Rolled

It should be noted that in 5-year time span before the barrier was installed, there were 57 rollovers within the median of these sections. While it is unclear whether the barrier contributed to the instability of the vehicle, it appears, based on the accident history that there was a reduction in the rate of rollovers. There were 1.51 rollovers per 100 Million Vehicle Miles Traveled (MVMT) before cable barrier installation and only 1.25 rollovers per 100 MVMT after. This being the case, it does not appear that the barrier increases the likelihood of a rollover occurring.

There were 22 barrier impacts that involved vehicles that rolled. One of these involved a fatality. In this accident, the driver made an emergency maneuver and there was evidence of wheel furrowing before the vehicle came into contact with the cable median barrier. The passenger who perished was ejected from the vehicle. 
- Blown Tire

Six accidents involved vehicles that had blown or lost a tire and then struck the barrier. Of these, one vehicle went through the barrier and one vehicle rolled.

- Larger than Design Vehicle

It should be noted that the design vehicles for the cable barrier system are a 4400pound truck and an 1800-pound small car. Both design vehicles are tested at 100 kilometers an hour however, the design truck is tested impacting the barrier at 25 degrees while the small car is tested at 20 degrees.

Five accidents involved vehicles that were heavier than the barrier system's design vehicle. None of these vehicles penetrated the barrier. Only one of these accidents resulted in an injury.

- Motorcycles

None of the accidents involved motorcycles.

\section{Driver:}

- DUI or Drugs

Eight accidents involved vehicles that were driven by motorists cited for driving while intoxicated or under the influence of drugs.

- $\quad$ Sleep or Inattention

Four accidents involved vehicles that were driven by individuals that were cited for driving while asleep or inattentive.

- Emergency Maneuver

Eleven accidents involved motorists that made emergency maneuvers. This can result in vehicle departure angles that exceed those experienced in accidents involving sleeping or inattentive motorists. This is due to the very nature of emergency maneuvers. One accident resulted in a fatality (see Vehicle Rolled) and one resulted in a possible injury.

- Speeding Thirteen accidents involved motorists that were cited for speeding. One accident resulted in a vehicle that went through the barrier and was involved in a head on accident. The head on accident only resulted in possible injuries. Two of the thirteen vehicles were heavier than the design vehicle of the barrier. Neither of these heavy vehicles went through the barrier.

- $\quad$ Road Rage or Reckless

Three accidents involved motorists that were cited for road rage or reckless driving. 


\section{Weather:}

- Snow, Hail, or Ice

Four accidents involved vehicles that were traveling in conditions involving snow, hail, or ice. Two were heavier than the design vehicle for cable barrier. All drivers were cited for speeding (too fast for conditions). None of the four vehicles penetrated the barrier. None of the accidents resulted in an injury.

\section{CONCLUSIONS AND RECOMMENDATIONS}

The installation cost was calculated to be approximately $\$ 44,000$ per mile. The average cost per repair was found to be $\$ 733$ and the maintenance repair cost per mile was found to be $\$ 2,570$ annually. The time between cable barrier damage notification and repair was estimated to be about 2 days. While the accident data shows that the number of accidents increased noticeably, the number of severe accidents (fatal and disabling) decreased significantly. This resulted in a societal benefit of cable median barrier calculated to be $\$ 420,000$ per mile annually. Given the societal benefits associated with the use of cable median barrier at locations having prior cross median accidents, cable median barrier has been found to be a cost effective solution to median crossover accidents. 


\section{REFERENCES}

1. Roadside Design Guide. AASHTO, Washington, D.C., 1988.

2. Ross, H.E., Jr., D.L. Sicking, R.A. Zimmer, and J.D. Michie. NCHRP Report 350:

Recommended Procedures for the Safety Performance Evaluation of Highway Features. TRB, National Research Council, Washington D.C., 1993.

3. Hunter, W.W., Stewart, J.R., Eccles, K.A., Huang, H.F., Council, F.M., Harkey, D.L, ThreeStrand Cable Median Barrier in North Carolina. In Transportation Research Record: Journal of the Transportation Research Board No. 1743, TRB, National Research Council, Washington, D.C., 2001, pp.97-103.

4. Sposito, B., Three Cable Barrier Still a Hit. In Oregon Department of Transportation Research Notes, RSN 00-06, Salem Oregon, 2000.

5. Albin, R.B., Bullard, D.L., Jr., Menges W.L., Washington State Cable Median Barrier. In Transportation Research Record: Journal of the Transportation Research Board No. 1743, TRB, National Research Council, Washington, D.C., 2001, pp.71-79.

6. Ray, M.H., Weir, J.A., Unreported Collisions with Post-and-Beam Guardrails in Connecticut, Iowa, and North Carolina. In Transportation Research Record: Journal of the Transportation Research Board No. 1743, TRB, National Research Council, Washington, D.C., 2001, pp.111-119.

7. Horne, D.A. Acceptance of New York Three-Strand Cable Terminal. Office of Highway Safety Infrastructure, FHWA, U.S. Department of Transportation, Washington, D.C., 2000. 


\section{LIST OF TABLES}

FIGURE 1 Typical cable median barrier installation and details

FIGURE 2 Washington State cable barrier terminal

FIGURE 3 Washington State cable barrier transition to W-beam guardrail

FIGURE 4 Before and after accident comparison

\section{LIST OF FIGURES}

TABLE 1 Cable barrier maintenance data

TABLE 2 Median accidents before and after the installation of cable barrier TABLE 3 Segment Characteristics

TABLE 4 Accident Societal Costs 